Literatura y Lingüística $\mathrm{N}^{\circ} 24$

ISSN 0716-5811 / pp. 121-141

\title{
Las macroformas textuales de los Derechos Humanos. Chile, 1973-1980*
}

\author{
Freddy Timmermann ${ }^{* *}$
}

\section{Resumen}

El presente artículo analiza la forma en que se proyectan discursivamente los Derechos Humanos en el Régimen Cívico-Militar, entre los años 1973 y 1980. Por medio del Análisis Crítico de Discurso y de proyecciones historiográficas, se vinculan los elementos textuales de sus documentos oficiales más significativos con los diversos contextos de poder por los que se transita en la época en estudio. Con ello, se perciben sus coherencias doctrinales y simbólicas, así como el carácter de la "democracia protegida" propuesta y su directa relación con las políticas gremialistas, neoliberales y de la Doctrina de Seguridad Nacional con que se opera.

Palabras clave: Derechos Humanos, Régimen Cívico-Militar, Declaración de Principios, Democracia Protegida, gremialismo, neoliberalismo

\section{The textual macrostructures of the human rights. Chile, 1973-1980}

\begin{abstract}
This article discusses how Human Rights can be interpreted as elements of discourse in the Civil-Military Regime, between 1973 and 1980. Through both Critical Discourse Analysis and history-graphical projections, the contextual elements from the most significant documents are linked to the diverse empowerment doctrines enforced at that time. In addition, doctrinal and symbolic coherence are perceived, as well as and the character of the 'protected democracy' proposed and its direct relationship to neoliberal labor policies, and the National Security Doctrine within which it operates.
\end{abstract}

Keywords: Human Rights, civic-military regime, declaration of principles, protected democracy, labor union, neoliberal movement

Recibido: 05-04-2011 Aceptado: 07-07-2011

* El presente trabajo recoge contenidos de la Tesis Doctoral "La Declaración de Principios de la Junta Militar. Chile, 1973-1980" (Departamento de Historia. Facultad de Filosofía y Humanidades. Universidad de Chile, 2009). Se expuso en el Sexto Encuentro Nacional de Estudios del Discurso (2010), "Los Estudios del Discurso en el Bicentenario", Santiago, 27-28 de septiembre 2010 (Departamento de Lingüística. Facultad de Filosofía y Humanidades de la Universidad de Chile).

** Doctor en Historia. Académico de la Universidad Católica Silva Henríquez. freddytimmermann@hotmail.com 
Las macroformas textuales de los Derechos Humanos. Chile, 1973-1980 / Freddy Timmermann

\section{Introducción}

El objetivo de este estudio es analizar la proyección discursiva de los Derechos Humanos en el Régimen Cívico-Militar ${ }^{1}$, mediante el Análisis Crítico de Discurso y proyecciones historiográficas de sus documentos oficiales más significativos, estableciendo sus coherencias doctrinales y simbólicas en función de los diversos contextos de poder por los que se transita entre los años 1973-1980.

El presente trabajo busca demostrar que, en los principales discursos de los documentos oficiales del régimen cívico-militar de los años 1974 a 1980, en el tratamiento del tema Derechos Humanos (DDHH), existe una instrumentalización constante de su percepción, establecida en función de la coyunturas inmediatas por las que transita el poder político, pero también, al mismo tiempo, existe una coherencia doctrinal y simbólica temporalmente más amplia, observable en el período 1973-1980, variable esta última en los énfasis de sus contenidos. Factualmente, ambas recogen la necesidad de legitimar el ejercicio del principal dispositivo de poder del período, la violencia, inserta en los presupuestos de la Doctrina de Seguridad Nacional, pero también proyectada a partir de elementos del integrismo católico del gremialismo y del esencialismo derivado del mercado del neoliberalismo. Ambos permiten articular, pese a sus tensiones y disensos, un proyecto fundacional del régimen.

Se trabajan los documentos con el Análisis Crítico de Discurso, porque se estudia el lenguaje como práctica social y se considera que el contexto de su uso es central para su comprensión, interesándose de modo particular en la relación entre el lenguaje, el poder, la historia y la ideología (Wodak, 2003: 17-21). Inicialmente, se precisan desde el discurso los "acontecimientos" históricos. Un acontecimiento es un hecho histórico, "un hecho notado, señalado a nuestra atención, registrado, convertido de un modo u otro en visible para nuestra mirada, por una luz tal vez fortuita, en medio de la masa de esos hechos tal vez innumerables que, a cada instante, conforman la historia ideal y completa del mundo". Lo que decidirá la importancia del "acontecimiento" son "las consecuencias que se deriven o no de él” (Braudel, 2002: 24-27). Se podría decir que las "palabras" son, en el texto, los "acontecimientos", pese a que estos aún no son contextualizados fuera de él. Las tensiones entre las palabras

1 Se define como Régimen Cívico-Militar porque el gremialismo fue el partido político no oficial que organizó en no poca medida sus espacios administrativos y el neoliberalismo sus políticas económicas. Habría que agregar el papel que cumplieron los civiles en el Poder Judicial y el del grupo "Patria y Libertad" en los organismos de seguridad, entre otros. La Declaración de Principios habla de formar "un nuevo y gran movimiento cívico militar" (1974: 29).

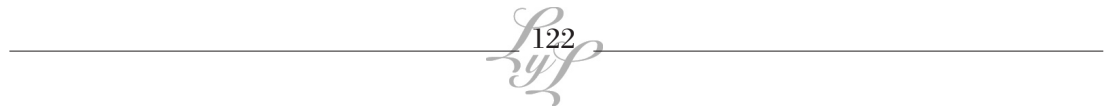


y las realidades estudiadas, en términos de dispositivo de poder, se analizan, primero, en función de las "palabras llenas" (sustantivos, adjetivos, verbos) $)^{2}$. Posteriormente, interesa trabajar aquel aspecto que dé cuenta de emisiones completas de la estructura lingüística -secuencias de oraciones- y las relaciones semánticas entre estas, que permitan generalizar respecto a las oraciones compuestas y secuencias de oraciones, propiedades lingüísticas como la noción de macroestructura de fragmentos y párrafos, para, a partir de lo anterior, elaborar modelos cognoscitivos de desarrollo, producción y comprensión, estudiándolo en el contexto social interaccional e institucional (Van Dijk, 1997: 9, 17-19).

Finalmente, se determina el "contexto de situación", que se refiere a aquellas características pertinentes al discurso que se está produciendo y pueden ser concretas e inmediatas, aunque también abstractas y remotas (Halliday, 1994: 42, 43). Entonces, se proyectan los datos historiográficamente, sincrónica y asincrónicamente en función de los presupuestos de la Nouvelle Histoire (Le Goff-Chartier-Revel, 1988), la Historia Cultural (Burke, 2006), y la hermenéutica de Paul Ricoeur (2008). La interrelación de los contextos internos del texto con su utilización pragmática se realiza en función de la teoría del poder de Michel Foucault, ampliada por S. Jaeger (2003). Por el espacio aquí disponible, se exponen fundamentalmente los resultados de su aplicación, cuyos presupuestos empíricos, teóricos y metodológicos figuran en forma íntegra en la Tesis Doctoral La Declaración de Principios de la Junta Militar. Chile, 1973-1980 (2009).

\section{Realidad y Destino de Chile ${ }^{3}$}

Hacia mediados de octubre de 1973, se transita desde una tendencia "restauradora" a una "fundacional" y a una consolidación lenta de la hegemonía del poder personal de Pinochet, del Alto Mando del Ejército

2 Se desarrolla un trabajo de correferencia léxica buscando establecer una cohesión léxica, determinada por una semejanza referencial dentro del texto. Se sigue lo planteado por KerbratOrecchioni, C. (1997: 43-150), realizando algunas adaptaciones de acuerdo a las necesidades de la presente investigación.

3 Es un documento de 64 páginas, dado a conocer el 11 de octubre de 1973. Trata dos temas básicos: la situación del país en el presente y la percepción que se tiene del futuro. Son discursos, elaborados por separado para atender distintas realidades, dirigidos a diferentes receptores: el país, la comunidad internacional y el país nuevamente. El primero es el "Texto de la intervención del Presidente de la Junta de Gobierno de Chile, General Augusto Pinochet Ugarte, en el Salón de Honor del Edificio Diego Portales al cumplirse un mes del pronunciamiento de las Fuerzas Armadas y Carabineros de Chile". El segundo es el "Texto de la Intervención del Canciller de Chile, Vicealmirante don Ismael Huerta, ante la Asamblea General de las Naciones Unidas". El tercero es la "Exposición al país del estado de la Hacienda Pública, efectuada por el Ministro de Hacienda Contraalmirante Lorenzo Gotuzzo". 
y de la Junta de Gobierno. Por ello, cuando la Comisión Constitucional instalada en octubre de 1973 fue controlada por Pinochet y experimenta la injerencia de Jaime Guzmán, la preocupación por la "democracia" derivó en una apuesta más antiliberal, aunque no se establece claramente la tendencia fundacional. Por ello es que en Realidad y Destino de Chile, el tema de los DDHH no aparece en el primer discurso, políticamente el más importante. En el segundo, se sostiene que "desde los albores de su vida independiente, Chile se ha preocupado de resguardar, tanto en su Carta Fundamental como en la realidad, los derechos esenciales de la persona humana y el respeto al bien común". Más directamente, se afirma: "Debemos actuar de buena fe y reconocer que los progresos de la comunidad internacional organizada se logran principalmente por el acatamiento de las resoluciones básicas de la organización, como la declaración sobre la concesión de independencia de los países y pueblos coloniales, la Declaración sobre los Derechos Humanos..." (Realidad y Destino de Chile, 1973:26). Esta proyección es pensada para legitimar lo sucedido en Chile en el ámbito externo porque, pese a afirmar que se debe "acatar" lo que las Naciones Unidas sostienen al respecto, lo que realiza factualmente el Régimen Cívico-Militar va en una dirección distinta pues, hasta fines de octubre, el dispositivo de poder predominante es el ejercicio masivo de la violencia, operando con objetivos casi completamente militares y no políticos (Timmermann, 2008: 155-190). Se comprende, entonces, que los DDHH no necesiten entonces una mayor proyección conceptual ligada a una tendencia propiamente fundacional. Si se mencionan es para neutralizar un espacio de poder externo al país que afecta al Régimen Cívico-Militar, las Naciones Unidas, en cuyo seno ya se gestaban críticas por la violación extrema de estos.

\section{La Declaración de Principios de la Junta Militar de Gobierno ${ }^{4}$}

\section{El Orden Jurídico}

En marzo de 1974, la tendencia fundacional del Régimen CívicoMilitar se ha consolidado desde el gremialismo. La Declaración de Prin-

4 Dada a conocer el 11 de marzo de 1974, a seis meses del golpe cívico-militar, es redactada principalmente por Jaime Guzmán (Cristi, 2000, 37), aunque Julio Canessa afirma que el COAJ también participó en su redacción (Arancibia-Balart, 2006: 197), es un texto oficial de un Gobierno que se instala por medio de la fuerza en el poder y que procura legitimar este hecho proponiendo una percepción del mundo y un determinado proyecto político, social y económico, en sus líneas generales. Se aprecian en él retóricas distintas. Una es filosófica, con presencia de elementos trascendentes, antagonismos y miedos evidentes; la otra, es técnica, realista, pragmática, segura. 
cipios es su expresión más lograda. La quinta "conclusión" del capítulo III, "Inspiración Nacionalista, Realista y Pragmática", refiere el tema de los DDHH que, al ser incluido forzadamente en el texto -pues rompe su coherencia temática-, evidencia que necesita ser expuesto, aclarado y legitimado 5 . La frase "derechos humanos" aparece titulando el subcapítulo "Un Orden Jurídico Respetuoso de los Derechos Humanos: Marco para el actual Gobierno" (Declaración de Principios, 1974: 26, 27), expuesto como parte de la "realidad chilena" en que la "inspiración nacionalista, realista y pragmática" "conjuga" "las constantes de nuestra historia". Lo anterior llama la atención por cuanto se enfatiza en un documento oficial que formula los "principios" directrices fundacionales por primera vez desde el 11 de septiembre de 1973 en forma sistematizada ${ }^{6}$, en momentos en que el Régimen Cívico-Militar ya era severamente cuestionado internacionalmente por los abusos en que incurre al respecto.

El tema en sí es el "orden jurídico". Los "derechos humanos" son mencionados dos veces, en forma casi tangencial, sin destacarlos con comillas o negrillas, como sí se hace con otros contenidos. Sólo una atenta lectura permite precisar que en el "respeto" a los "derechos humanos" se incluye "la libertad de conciencia y el derecho a discrepar" y que "ese respeto" se observa en el "aprecio profundo que el chileno siente por la dignidad espiritual de la persona humana y, consiguientemente, por sus derechos fundamentales". El "orden jurídico" es un reflejo de ello. Finalmente, se sostiene que es en el "respeto por los derechos humanos, más que en su tradición de generación popular y sucesión constitucional de los Gobiernos donde debe encontrarse la savia y la médula de la democracia chilena" (Declaración de Principios, 1974: 26). Nunca se vuelve sobre el tema de los DDHH. Es decir, el documento no facilita su comprensión conceptual, enfatizando de hecho, según se verá, su proyección en función de la mantención del orden socio-político autoritario sustentado en una brutal represión.

\section{La Democracia}

Por el orden autoritario que se impone en el Régimen Cívico-Militar, se valida una "democracia" sustentada no en la "generación popular y sucesión constitucional de los Gobiernos" sino, paradójicamente, en el

5 Prácticamente, se reitera lo antes sostenido en el capítulo II ", "Concepción del Hombre y de la Sociedad", en su tercer subcapítulo, "El fin del Estado es el Bien Común general", respecto a que el Estado debe respetar los derechos naturales del hombre al actuar por el "bien común" (Declaración de Principios, 1974: 14-16).

6 Elementos más dispersos figuran en Realidad y Destino de Chile. 
"respeto" a los "derechos humanos". Quien determina la forma en que se definen y "respetan" es una elite -fundamentalmente Pinochet, el Comité Asesor de la Junta y la Junta de Gobierno, pero también el Alto Mando del Ejército, Jaime Guzmán y los gremialistas- que, en aquellos momentos, posee el poder y que se supone portadora, al menos, de la definición de "la dignidad espiritual de la persona humana". Con ello, se introduce una emoción concreta en el tiempo presente, el miedo a ver vulnerados los "derechos humanos", para estructurar un disciplinamiento destinado a generar obediencia política, porque al miedo se suma la dependencia de la elite mencionada. También es un temor al pasado pues, para legitimar la democracia propuesta, se le atribuye al Régimen Cívico-Militar un mayor respeto por los "derechos humanos" que el anterior sistema político (Declaración de Principios, 1974: 26, 27). Esta dependencia autoritaria resta a los ciudadanos la posibilidad de construir su propio orden, otorgándoles socialmente un orden concedido.

\section{El Absoluto Trascendente}

Este sentimiento, el "aprecio profundo que el chileno siente por la dignidad espiritual de la persona humana y por sus derechos fundamentales", forma parte del "nacionalismo" que se caracteriza en el capítulo III -Inspiración Nacionalista, Realista y Pragmática- y es el que permitirá lograr lo planteado en la primera "conclusión", el objetivo fundamental de la reconstrucción, hacer de Chile una gran nación. Conduce al "más preciado" del "Gobierno de las Fuerzas Armadas y de Orden", alcanzar la "unidad nacional" (Declaración de Principios, 1974: 21-37). Esta se alcanzará no por medio de la anterior democracia sino de una sustentada en un sentimiento que viene del pasado, que forma parte del "nacionalismo", antes derivado por el autor de la "concepción cristiana", es decir, de Dios.

Si la "unidad nacional" se ha extraviado, al permanecer el país bajo el concepto de democracia basado en la "tradición de generación popular y sucesión constitucional de Gobiernos”, la forma de recuperarla es retornando al pasado en la búsqueda de aquellos sentimientos nacionalistas que "más que una ideología", son "un estilo de conducta, la expresión genuina del ser de la Patria y del alma de su pueblo" (Declaración de Principios, 1974: 23). Se cree en esta especie de constante que opera en forma trascendente ${ }^{7}$, en su recuperación. Pero no se detallan los mecanismos

7 En la inmanencia, el ser queda circunscrito a, o mejor, inscrito en lo experimentable o finito, predicándose desde la vida, puesto que su realización o ejercicio no pone al efecto como existente fuera de ella sino que significa autorrealización (activo inmanens), donde el viviente es a la vez agente y paciente o sujeto actuado. Entenderemos por trascendencia las experiencias 
históricos concretos mediante los cuales la Junta logrará concretarla, sino indirectamente, según se verá. Este silencio del documento, sin embargo, es funcional a la situación en que se inscribe contextualmente, pues permite no lesionar los derechos de quienes poseen de facto el poder dejando, además, abierta la posibilidad de modificar los mecanismos discursivos mencionados en los futuros escenarios de poder.

\section{Orden, represión, democracia}

El carácter de la "democracia" propuesta, para recuperar la "unidad nacional", queda clarificado en el documento al sostener que el "respeto por la libertad de conciencia y el derecho a discrepar" debe "ser preservado por el Estado de Derecho que el movimiento del 11 de septiembre se propone recrear", siendo mantenido "dentro de las medidas de emergencia que el mismo contempla". Se afirma que "Los derechos humanos deberán reforzarse para que su ejercicio pueda ser efectivamente disfrutado por todos, y ampliarse a sus manifestaciones sociales más modernas". También, que "El derecho a discrepar deberá ser mantenido, pero la experiencia de los últimos años indica la necesidad de fijar los límites admisibles de esa discrepancia". ¿Se procura así validar las restricciones que los DDHH padecen, por una "emergencia" que vive el país? Sin duda. Se afirma que "No puede permitirse nunca más que, en nombre de un pluralismo mal entendido, una democracia ingenua permita que actúen libremente en su seno grupos organizados que auspician la violencia guerrillera para alcanzar el poder, o que fingiendo aceptar las reglas de la democracia, sustenten una doctrina y una moral cuyo objetivo es el de construir un Estado totalitario". Esta construcción legitimadora es culminada al afirmar que "De ello se desprende que Chile no es neutral frente al marxismo" -resaltado con negrillas-(Declaración de Principios, 1974: 26, 27). Queda en evidencia que es esta afirmación la que se privilegia y no un concepto específico de los DDHH, el cual sólo se comprende en función de esta conclusión final, que ha sido construida teniendo en el principio y en el fin del subcapítulo un telón de fondo, dos amenazas básicas, el temor a Dios y al marxismo. De esta forma, de facto, instalando un miedo cotidiano de vivencia sociopolítica, se impone una aprehensión del concepto DDHH, también susceptible de ser modificada posteriormente.

Se tiene la impresión de que el tema de los DDHH es tratado en la DP debido a una imposición política puntual más que formando parte

que sobrepasen los límites que señala la inmanencia, lo experimentable, lo finito (Pellegrino, 1983: 543-555). 
de un planteamiento sistemático. El tema se trata sin un nivel de precisión que "obligue" al poder reinante a respetarlos, a vulnerar con ello la política represiva que efectuaba. Es por ello que la proyección de los elementos de Seguridad Nacional relacionados con la "sanción drástica" que se afirma se aplicará ante toda "indisciplina o anarquía"8 nunca va a ser explicitada. Son los momentos en que Pinochet ya ha controlado al Ejército, dando de baja, enviando a embajadas o eliminando a los oficiales que manifiestan disenso. Por medio de la DINA, vigila a las restantes FFAA, Carabineros, elites de gobierno y oposición. Va consolidando su hegemonía, junto a la Junta, al Alto Mando del Ejército y al gremialismo dirigido por Jaime Guzmán.

\section{El Objetivo Nacional ${ }^{9}$}

Ante el fracaso, a inicios de 1975, del modelo económico-social de tendencias estatistas con fines de justicia social, el Gobierno opta por el neoliberalismo. Desde poco antes, el gremialismo ha ido implementando la "regionalización", es decir, el manejo de la administración burocrática del régimen, fundamentalmente con ODEPLAN y las municipalidades. La violencia ha pasado a un ejercicio más selectivo y societalmente menos abierto, incluyendo objetivos situados fuera del país. La DINA, dependiente de Pinochet, la ha monopolizado, generando no pocas resistencias al interior del régimen. Por ello, el Objetivo Nacional no refiere los DDHH. Sólo afirma que "Se desarrollará un auténtico Estado de Derecho, donde existe plena vigencia de los derechos naturales de la persona humana, tanto individualmente considerada como en su proyección social, sin perjuicio de los límites que el bien común imponga a su ejercicio" (1975: 11). Esta última frase, "sin perjuicio de los límites que el bien común imponga a su ejercicio", significa que la Seguridad Nacional tendrá preeminencia en sus tareas por sobre "los derechos naturales de la persona

8 La tercera "conclusión" en que se "inspira" el "nacionalismo" -Gobierno Autoritario, Impersonal y Justo- es iniciada con una legitimación centrada en el pasado histórico del país, el gobierno de Diego Portales. Esta legitimación es unida, a continuación, al "Gobierno de las Fuerzas Armadas y de Orden", el que "guía". Por ello, ejercerá "con energía el principio de autoridad, sancionando drásticamente todo brote de indisciplina o anarquía" (Declaración de Principios, 1974: 23).

9 Es un documento de 48 páginas, fechado el 23 diciembre de 1975. La redacción de la "introducción" da a conocer elementos formales de carácter jurídico en que se presenta primero el cargo que faculta a quien expone; luego, sus razones y, finalmente, el documento denominado Objetivo Nacional del Gobierno de Chile. También aquí existen redacciones distintas: técnica y legal la primera; con elementos trascendentes más amplios la segunda y una mezcla de ambas la tercera, lo que evidencia que son al menos dos los autores o grupos de ellos quienes las redactan. 
humana", pues el documento está permeado fundamentalmente por esta doctrina, que adquiere preeminencia para sus redactores militares del Comité Asesor de la Junta (COAJ) (Arancibia-Balart, 2006:197). Es un documento que expone los puntos de vista de los militares que se encuentran cercanos a Pinochet, lo que no significa que estos sean plenamente considerados por él, pues el desarrollo de los contextos de poder ha comenzado a modificar la hegemonía antes mencionada.

Por eso es que, dados los esfuerzos que realiza el Gobierno para neutralizar la imagen del país por la violación de los DDHH que realizaba, llama la atención el énfasis mencionado del COAJ, aunque también podría sostenerse que sus redactores proyectan desde su disciplina sus ideologías, sin preocuparse mayormente por los efectos políticos que sus afirmaciones generen, en la confianza de controlar un sistema que no establece disenso alguno al respecto y en el afán de exponer sus puntos de vista, que comenzaban a ser antagónicos con los que planteaban el gremialismo y el neoliberalismo desde el segundo semestre de 1975.

En el documento también existe una ausencia de conceptos vinculados a una democracia de origen popular. En una dirección aparentemente contraria, según se verá, Pinochet da un paso trascendental al respecto, pues en su discurso el 11 de septiembre de 1975 anunció que se promulgarían seis o siete Actas Constitucionales, las primeras durante el primer semestre de 1976. Daba la impresión que el régimen iniciaba el camino constitucional hacia la normalidad, pero, de hecho, lo que se aprecia es la ampliación de un "pluralismo limitado" a las elites civiles gremialistas y neoliberales, con marcados predominios hegemónicos en la "democracia" que se pretende imponer. De esta forma, la ideología institucionalizadora o "aperturista" comienza a desplazar a la Doctrina de Seguridad Nacional.

\section{El Discurso de Chacarillas ${ }^{10}$}

Se pierde notoriamente en este documento el vínculo con elementos trascendentes percibidos en la Declaración de Principios, como el "nacionalismo" y la "concepción cristiana" lo que evidencia, al igual que en el Objetivo Nacional, la disminución de la influencia doctrinal del gremialismo. El Gobierno comienza a otorgar preeminencia al fortalecimiento factual del neoliberalismo. Predominan desde entonces en forma

10 El Discurso de Chacarillas es breve, de seis páginas. Elaborado en julio de 1977, caracteriza la "nueva democracia" propuesta por el Régimen Cívico-Militar, estableciendo la gradualidad en que se implantará. 
más sistemática los elementos inmanentes, enfatizándose un contexto específico, el cual lleva a sostener una determinada percepción de los DDHH. Nunca se define lo que se comprende por ellos. Su sentido, se afirma, se ha comprendido, en "una amarga experiencia reciente". También se expresa que "Resulta incomprensible que toda restricción a determinados derechos de las personas se enjuicie como una presunta trasgresión a los derechos humanos, mientras que la actitud débil o demagógica de muchos gobiernos frente al terrorismo no merezca reparo alguno en la materia, aun cuando es evidente que ella se traduce en una complicidad por omisión, con una de las formas más brutales de violación de los derechos humanos". Con ello también se justifican "las limitaciones excepcionales que transitoriamente hemos debido imponer a ciertos derechos", más aún al contar con el "respaldo de la juventud y del pueblo de nuestra Patria", quienes han visto en ellas "el complemento duro pero necesario para asegurar nuestra Liberación Nacional, y proyectar así amplios horizontes de paz y progreso para el presente y futuro de Chile".

Por ello, se sostiene, "Es posible que nuestro enfoque más amplio y profundo en esta materia sea difícil de comprender para quienes no han vivido un drama como el nuestro". Agrega, "Por esta razón, dispuse recientemente que renunciáramos a la solicitud de un crédito externo, cuyo otorgamiento pretendió condicionarse públicamente a un examen de un Gobierno extranjero acerca de la evolución de nuestra situación en materia de derechos humanos. Estoy cierto de que en esta actitud me acompaña el país entero, porque si hay algo que de verdad todo chileno tiene muy claro es que la dignidad de nuestra patria no se transa ni se hipoteca ante nada ni frente a nadie". Finalmente se afirma que "Menos aceptables son todavía los intentos de intervención foránea, cuando la causa que se invoca para ella es la supuesta defensa de los derechos humanos. Nuestra historia y nuestra idiosincrasia se han forjado en el respeto a la dignidad del hombre. Sólo una amarga experiencia reciente, que estuvo a punto de conducirnos a la guerra civil, nos ha hecho comprender que los derechos humanos no pueden sobrevivir en un régimen político y jurídico que abre campo a la agresión ideológica del marxismo-leninismo, hoy al servicio del imperialismo soviético, o a la subversión terrorista, que convierte a la convivencia social en una completa anarquía"11.

11 Anoche en Chacarillas S.E. indicó Grandes Líneas Institucionales, 1977: 33 (en adelante, Discurso de Chacarillas). 
Se justifican los DDHH vulnerados asumiendo una posición defensiva. Sus argumentos exponen un enemigo -la URSS- en momentos en que se producen críticas de parte de las elites cívico-militares por las acciones de la DINA, lo que se suma a lo sostenido por la Iglesia Católica y la Vicaría de la Solidaridad, y a que la política de EEUU, centrada en otros objetivos, lejanos al anti-comunismo acentuado de otras épocas de la Guerra Fría, presiona al gobierno por el esclarecimiento del asesinato de Orlando Letelier. De hecho, la administración Carter trabaja promoviendo el respeto por los DDHH, hecho que tiene consecuencias directas que sí afectan el régimen cívico-militar (Procacci, 2001: 488, 489). Por ello, no parece posible sostener que los argumentos del Discurso de Chacarillas pudiesen lograr modificar las severas críticas que se generaban por la violación de los DDHH por parte del régimen. Estos llaman aun más la atención si observamos que su principal redactor, al relevar el papel de los militares en la "protección" de los DDHH, menoscaba la posición de quienes en esos instantes buscaban generar una "institucionalización" del régimen que perseguía, justamente, controlar el poder que ejercían.

Escrito por Jaime Guzmán, que busca generar mayores influencias para el gremialismo y una apertura de los militares hacia los civiles, tal vez su deseo de enfatizar la "democracia protegida" sea el eje sobre el que gira el documento, lo que justificaría su posición doctrinal. Pero está considerando una "democracia protegida" por los militares, hecho que lo lleva a ser también prudente en no producir tensiones con ellos. Opta por mantener las amenazas represivas al mismo tiempo que sostiene que la "nueva democracia" será "Autoritaria y que debe disponer de una autoridad fuerte y vigorosa". Sin embargo, en lo inmediato, no menciona su relación con la "seguridad nacional". Sólo afirma que en la etapa de "normalización las Fuerzas Armadas y de Orden se "reservarán" "constitucionalmente" "el papel de contribuir a cautelar las bases esenciales de la institucionalidad y la seguridad nacional en sus amplias y decisivas proyecciones modernas" (Discurso de Chacarillas, 1977: 33), sin detallar la forma en que ello operará. Es un énfasis en el tutelaje que los militares desean imponer en el futuro sobre los civiles. Sin embargo, en aquellos instantes tampoco puede soslayar las críticas de la Iglesia Católica chilena e internacionales ante la masiva violación de los DDHH, por un lado, y la necesidad del Gobierno y elites neoliberales de internacionalizar la economía que, por lo anterior, experimentaba dificultades, por otro. En lo inmediato, ello lleva a Pinochet a modificar el ejercicio de la violencia, reemplazando la DINA por la CNI y a Manuel Contreras por Odlanier 
Mena, crítico a su gestión ${ }^{12}$. También a implementar la "institucionalización del régimen" o, al menos, a enunciarla. El Discurso de Chacarillas recoge estas tendencias, aunque las perspectivas en que se proyectan sus contenidos no sean las mismas para Pinochet y Guzmán. Sin embargo, las dificultades recién comienzan.

\section{Visión Futura de Chile ${ }^{13}$}

En diciembre de 1977, la ONU condena a Chile por la violación de DDHH con 96 votos a favor. Pinochet, posiblemente por sugerencia de Jaime Guzmán (Martorell-Guerra: 21) ${ }^{14}$, informa a la Junta que realizaría un plebiscito al respecto, que después se transformó en una "Consulta", pues la Constitución no lo contemplaba. Así esperaba mostrar al mundo el rechazo del país a la condena, el respaldo que tenía el gobierno y legitimar ante la ciudadanía su liderazgo. Se oponen Jorge Alessandri, Leigh y Merino, pero Pinochet no retrocede, pues sabe que lo que estaba en juego, más allá de la votación en la ONU, era la permanencia de su propio poder. El 4 de enero de 1978 se realiza la Consulta. El texto del voto, que identificaba la defensa del país con Augusto Pinochet, decía: "Frente a la agresión internacional desatada en contra de nuestra Patria, respaldo al presidente Pinochet en su defensa de la dignidad de Chile y reafirmo la legitimidad del gobierno de la República para encabezar soberanamente el proceso de institucionalización del país". Frente a la alternativa "sí" había una bandera chilena y a la alternativa "no" un cuadro negro. Obtuvo un triunfo con el 75\% de los votos a favor. Pinochet, a la salida del Diego Portales, dijo: "¡Señores políticos, esto se les acabó a ustedes! ¡Ahora Chile es otro!”. Para él, el triunfo en la Consulta fue personal (Cavallo-Salazar-Sepúlveda, 1988: 179-186,188). En esta nueva posición de poder, toma represalias contra la Democracia Cristiana relegando al extremo norte a 12 personalidades políticas y del movimiento sindical (Huneeus, 2005: 151).

12 Sin embargo, en 1978 realizará, por expresa petición de Pinochet, la operación "retiro de televisores", destinada a mover los cuerpos inhumados después del golpe cívico-militar para tirarlos al mar, encubriendo así el severo atropello de los DDHH cometido por el Régimen Cívico-Militar los años 1973 y 1974 principalmente.

13 Es un documento de 52 páginas que expone una "Clase magistral de S. E. el Presidente de la República, general de Ejército Don Augusto Pinochet Ugarte, con motivo de la inauguración del año académico en la Universidad de Chile. 6 de abril de 1979". Continúa, prácticamente, la legitimación vista en el Discurso de Chacarillas, tendiente a instaurar una "democracia protegida".

14 Manuel Salazar sostiene que la idea de la Consulta fue de Guzmán, aunque "para consolidar la legitimidad de la dictadura" (1994: 125).

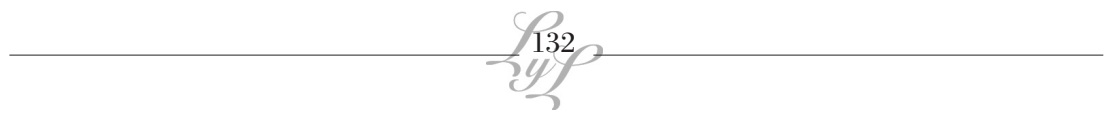


Pronto, sin embargo, otras dificultades tensionan aun más al régimen. La hegemonía Pinochet-Alto Mando del Ejército-Junta sufre un menoscabo más profundo el año 1978, por las consecuencias del crimen de Orlando Letelier en EEUU, país que ahora presiona para someter a proceso al general Manuel Contreras, ex jefe de la DINA, y por la disidencia decisiva de uno de los integrantes de la Junta Militar, el general Gustavo Leigh, todo ello en el marco de un posible enfrentamiento con Argentina -y Perú y Bolivia-. Los DDHH surgirán como tema central debido a que los familiares de los detenidos desaparecidos en mayo ocupan tres iglesias en Santiago y las oficinas de UNICEF, iniciando una huelga de hambre. Otro grupo marcha por el centro con carteles que reclaman por 618 desaparecidos. La prensa nacional por primera vez habló de los detenidos-desaparecidos (Harrington-González, 1987: 295, 299, 300). Pinochet y la Junta de Gobierno, el 18 de abril de 1978, promulgan el Decreto-Ley n 2191 que concede una amnistía a todas las personas que, en calidad de autores, cómplices o encubridores hayan incurrido en hechos delictuosos, durante la vigencia de la situación de Estado de Sitio, comprendida entre el 11 de septiembre de 1973 y el 10 de marzo de 1978, siempre que no se encuentren actualmente sometidas a proceso o condenadas. Incluyó a quienes a la fecha de vigencia del decreto ley se encuentren condenadas por tribunales militares, con posterioridad al 11 de septiembre de 1973. Sin embargo, el 9 de noviembre, el Comité Permanente de la Conferencia Episcopal expresa que en varias ocasiones se han dirigido a personeros del gobierno "acerca del problema de los desaparecidos" obteniendo respuestas que "no han sido satisfactorias". Agrega que "las personas llamadas detenidos-desaparecidos, que alcanzan a varios centenares, por los antecedentes reunidos y presentados al gobierno, y salvo algunas posibles excepciones, deben, a nuestro parecer, darse por detenidas por los servicios de seguridad del gobierno... El Sr. Ministro del Interior nos ha asegurado que, mientras él esté en el cargo, no se atropellarán los derechos humanos. Sabemos sin embargo que, en menor escala y en forma ocasional, se siguen violando estos derechos" (Conferencia Episcopal, 1978: 391-393).

El temor en las elites cívico-militares a que Chile fuera expulsado de las Naciones Unidas por la violación de los DDHH se había acentuado cuando se dio a conocer el informe de la comisión ad hoc que visitó el país en julio de 1978 y la votación de la tercera comisión, preludio de la principal de la Asamblea, en que se aprueba que se inste "una vez más" a las autoridades chilenas a que restablezcan y salvaguarden sin demora los DDHH más esenciales y las libertades más fundamentales. 
Posteriormente, 88 países apoyan esta percepción, condenando a Chile al respecto. En diciembre de 1978 la comunidad internacional premió a la Vicaría de la Solidaridad por su labor a favor de la protección a los DDHH. Las Naciones Unidas le entregaron el premio quinquenal en una ceremonia que celebraba el trigésimo aniversario de la Declaración de los Derechos del Hombre. Asistieron a Nueva York a recibir el galardón de manos del secretario general de la ONU, Kurt Waldheim, y del presidente de la Asamblea General, Indalecio Lievano, el Cardenal Silva Henríquez, Cristián Precht, Javier Luis Egaña y Augusto Góngora (Ahumada, 1989: 156). Ante las palabras del Cardenal en las Naciones Unidas, un grupo de católicos que trabajaban para el Régimen Cívico Militar -Julio Philippi, Jorge Cauas, Gonzalo Vial, José Piñera, Juan de Dios Carmona, William Thayer, Guillermo Pumpin y Jaime Guzmánexpresan en "El Mercurio" que "nada hay contrario a la doctrina o a la moral católicas en la orientación que inspira el contenido y forma de llevar a cabo el proceso de creación de una nueva institucionalidad para nuestro país, planteado por el Supremo Gobierno" (Santibáñez, 1978: 6). Sin duda, el tema de los DDHH para las elites es sensible, pues menoscaba su legitimación. Posteriormente, el 19 de octubre de 1979, el Cardenal Silva Henríquez recibiría en Viena el Premio Bruno Kreisky "por su valerosa acción de reconocimiento de los derechos humanos" (Pinochet de la Barra, 1987: 207, 208).

A mediados de año, en el núcleo interno del poder cívico-militar del régimen, Pinochet superará los obstáculos mencionados y saldrá muy fortalecido, como para destituir al general Gustavo Leigh. Por las objeciones que apuntan a su persona, en cuanto a sus intenciones de querer perpetuar un poder personal en un régimen que no respeta los DDHH, anuncia el proyecto de una nueva Constitución para 1979. Luego de la expulsión de Leigh de la Junta, se ha establecido un consenso en las elites respecto a ello, aunque el gremialismo no renuncia a la búsqueda de mayores espacios de poder para los civiles. Entonces, el neoliberalismo ya había consolidado su posición.

Este optimismo en el futuro bajo el liderazgo de Pinochet es el que recoge, en parte, Visión Futura a inicios de 1979. Para el régimen, la economía mostraba un buen desarrollo y se percibían legitimados por parte importante de la ciudadanía. Por ello se refuerza el presidencialismo y compara la etapa que se vivía con lo realizado por Diego Portales (Visión Futura de Chile, 1979: 4-6). Visión Futura posee una proyección aun más defensiva que el Discurso de Chacarillas, la que utilizará para generar obediencia política y legitimar el carácter "protegido" de la "democracia"

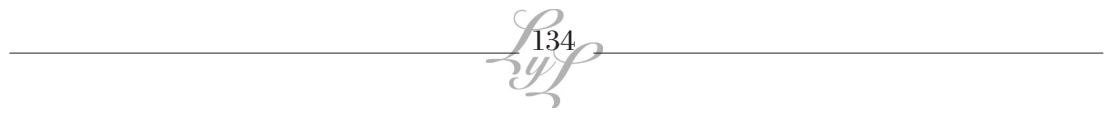


propuesta. No define DDHH. Afirma sí que "No tomar medidas preventivas frente a esta agresión soviética constituiría, por omisión, violar gravemente los Derechos Humanos más esenciales". También, que "En el campo de los derechos humanos, la campaña de propaganda a todo nivel nos ha imputado hechos ajenos a toda realidad, magnificando hasta dimensiones inverosímiles las consecuencias inevitables del enfrentamiento violento a que nos llevó, contra nuestra voluntad, la tentativa totalitaria que culminara el año 1973". "Podríamos extendernos largamente en una comparación entre lo ocurrido en nuestro país -donde un rápido proceso normalizador condujo, pasando por la liberación de todos los detenidos políticos, hasta una amplia Ley de Amnistía, cuya vigencia data ya de un año- y los horribles excesos que a diario tenemos noticia en otros lugares del mundo. Entrego este juicio a la honestidad de cada chileno y de cada observador objetivo, en la seguridad que, en lo íntimo de sus conciencias, llegan a conclusiones muy diferentes a aquellas que, por motivos políticos que no pueden ocultar, expresó la Comisión Ad Hoc de las Naciones Unidas. La verdad sobre Chile se abre paso día a día por sí sola, en cualquier lugar donde se examine con objetividad lo acontecido" (Visión Futura de Chile, 1979: 33, 45).

Se puede sostener que, por sobre los efectos externos que se puedan generar en los organismos internacionales que observan el atropello severo de los DDHH que ocurren en Chile, las posiciones del Discurso de Chacarillas y Visión Futura establecen las condiciones perceptivas que fortalecen los intereses económicos y políticos de las elites predominantes en el Régimen Cívico-Militar, preparando la relevancia que adquieren los militares en la Constitución de 1980 para ejercer la "tutela militar" del régimen político propuesto, determinando desde ya el carácter de la democracia que esta Carta Fundamental posibilitará. Por ello, se mantiene la presencia de un sentimiento, el miedo, no a Dios como en la Declaración de Principios pero sí al marxismo soviético, que, se sostiene, puede generar una regresión a condiciones "totalitarias" como las existentes antes de 1973. Este miedo al pasado se une al miedo al presente, a ser permeados por las "conclusiones" de instituciones como las Naciones Unidas sobre la situación de los DDHH del país. De esta forma, este carácter defensivo se utiliza, junto al miedo existente, para generar obediencia política y adhesión a la nueva institucionalidad que se prepara.

Aunque Visión Futura insiste en no poca medida en la "institucionalización" del Discurso de Chacarillas, existen divergencias importantes en las elites gobernantes respecto al contenido de la Carta Fundamental. Los neoliberales creen que la estabilidad social depende de mecanismos 
propios de coordinación, los que son generados por el mercado, no por la pura fuerza o ejercicio de la violencia, que es lo que sostienen los partidarios de la Doctrina de Seguridad Nacional (Timmermann, 2005: 212220), o por la voluntad política propuesta por el gremialismo. Critican la ideología institucionalizadora (constitucionalista, decisionista), centrada en preservar el equilibrio político más que en establecer reformas revolucionarias para generar un orden nuevo (Vergara, 1975: 215-229).

Los disensos mencionados se prolongarán hasta los últimos instantes en que se defina la Constitución de 1980. Imperarán en esta, sin embargo, los intereses de la Junta, del Alto Mando del Ejército y del neoliberalismo ${ }^{15}$. Los derechos fundamentales de la persona humana, parte del Estado de Derecho, son reconocidos, estableciéndose que son anteriores al Estado, emanando de la naturaleza humana. El artículo 19 sostiene que no se "podrán afectar... en su esencia, ni imponer condiciones, tributos o requisitos que impidan su libre ejercicio". Pero esto se contradice con el artículo 24 transitorio, que afirma que la autoridad del Presidente de la República "se extiende a todo cuanto tiene por objeto la conservación del orden público en el interior y la seguridad externa de la República, de acuerdo con la Constitución y las leyes", lo que viola la Declaración Universal de los Derechos Humanos, pues no hay recurso alguno, salvo el de reconsideración, que impida esta atribución. También, importantes derechos y garantías constitucionales son restringidos o suspendidos durante los Estados de Excepción constitucional. El Parlamento no concurre a limitarlo ni en su origen ni en su desarrollo. Así, con estas contradicciones, el monopolio de la fuerza que poseen las FFAA no es obstaculizado en la proyección jurídica de su ejercicio, obteniendo la necesaria capacidad para adaptarse a contextos cambiantes sin, aparentemente, lesionarla.

Es de esta forma como se consolida aún más la hegemonía PinochetAlto Mando del Ejército-Junta del primer contexto, al institucionalizar mediante la Constitución de 1980 su poder, cautelando también el ejercicio de la violencia mediante la legalización de los presupuestos básicos de la Doctrina de Seguridad Nacional y menoscabando, al mismo tiempo, la protección de los DDHH más esenciales. Ello es funcional con los intereses económicos y sociales del neoliberalismo que se consolidaba.

15 Robert Barros expone con detalle los contextos en que se redactaron las propuestas para elaborar la Constitución de 1980. Establece que las intenciones iniciales al respecto son diferentes a las interpretaciones que la oposición al Régimen Cívico-Militar les otorga (La Junta Militar. Pinochet y la Constitución de 1980. Editorial Sudamericana, Santiago, 2005, pp. 283-291). Sin embargo, estas últimas, en una proyección realista, tienen en cuenta el contexto de recepción en que operarán y consideran también a quienes detentarán el poder, para deducir factualmente el uso que de ellas se hará. 


\section{Conclusiones}

El Análisis Crítico de Discurso posibilitó estudiar en los documentos oficiales más importantes del Régimen Cívico-Militar del período 1973-1980 el uso del lenguaje político como práctica social, precisar sus contextos de producción y, por ello, los elementos propiamente historiográficos de estos "acontecimientos" discursivos, para determinar la relación dinámica entre el lenguaje usado y el poder que se desarrollaba. El estudio se centró en el tratamiento que se otorga al tema de los $\mathrm{DDHH}$, que posee directa relación con la violencia sociopolítica que se ejerce para establecer un determinado disciplinamiento destinado a imponer un tipo de democracia, "protegida". Esto permitió establecer los ritmos propios de la relación texto-contexto en tiempos específicos y, más ampliamente, en el período analizado (1973-1980).

Se demostró con la presente investigación que, aunque existe una variación de los énfasis en el significado de los DDHH en función de los contextos puntuales de poder, se percibe un discurso pleno de coherencia doctrinal en el período estudiado, pues la macroestructura que se configura muestra una concreta, funcional al contexto mayor de poder 1973-1980 que se desarrolla en el régimen. Esta contempla en los años 1973, 1974 y 1979 el uso de elementos simbólicos trascendentes como la concepción cristiana y el nacionalismo, proyectados en forma diversa en función de contextos de poder cambiantes, primero desde el gremialismo, para ser finalmente modificados en su interpretación sustentando el inmanentismo del neoliberalismo económico y social. Inicialmente, hasta comienzos de 1975, las legitimaciones de la violación de los DDHH en que se incurría se centraban en el pasado (anular a la Unidad Popular) para evitar que la "patria", "el nacionalismo" y "la concepción cristiana" no se vulneraran. Vemos, por lo tanto, una legitimación amparada en elementos trascendentes que permite evitar una clara definición de los DDHH, predominando en su aprehensión los elementos simbólicos mencionados. Sin embargo, la crisis económica de inicios de ese año modifica el peso en el régimen de las influencias de los civiles gremialistas. Sus elementos trascendentes comienzan a ser desplazados por los inmanentes propios de la Doctrina de Seguridad Nacional y del neoliberalismo, pues la violencia y la economía son los aspectos centrales en que el régimen percibe que se sustenta.

Con posterioridad a 1976, como el régimen comenzaba a experimentar un estancamiento en su desarrollo político, la hegemonía Pinochet-Alto Mando del Ejército y Junta se debilita. Pese a los riesgos 
y disensos internos, y aun cuando deben enfrentar las tensiones que se desarrollan por parte de los gremialistas para ampliar sus espacios de poder, las presiones diplomáticas de EEUU generadas por el crimen de Orlando Letelier y la salida del general Leigh de la Junta en 1978, permiten y alientan otras legitimaciones, provenientes, más que del mundo político gremialista, del ámbito económico neoliberal, que también cree, sin embargo, en un elemento trascendente de distinto esencialismo, el que sitúa en las leyes inmutables del mercado. Como el ejercicio de la violencia genera una anulación sociopolítica funcional al desarrollo de los planes neoliberales, el concepto de DDHH nuevamente no va a ser definido en los documentos oficiales y su proyección va a depender del grado de violencia que este autoritarismo necesite aplicar, esta vez con objetivos políticos más que de control militar, aunque este nunca está ausente. Se impone discursivamente una manipulación de la noción de DDHH, al evitar su definición, dificultar su comprensión, o proyectarla en función de contextos que generan una emoción, el miedo al desamparo de la elite que se erige como portadora del sentido de nación que Chile necesita. Precisamente, un elemento de la coherencia doctrinal presente desde la Declaración de Principios hasta Visión Futura es la ausencia de una vinculación de los DDHH con la noción de soberanía popular, de democracia liberal, lo que posibilita centrar en una elite su interpretación y proyección, ya sea apelando a elementos esencialistas trascendentes o inmanentes.

Si bien la apelación al miedo a Dios prácticamente ha desaparecido hacia 1979, el miedo al marxismo soviético es mantenido. Ambos, el miedo al desamparo de la elite y al marxismo soviético, legitiman la violación sistemática de los DDHH al final del período estudiado. También, discursivamente, su menoscabo, ocultamiento y deformación. Con ello, al mismo tiempo, se ampara el desarrollo del neoliberalismo y del "tulelaje" militar a los civiles que propugna la Doctrina de Seguridad Nacional.

\section{Bibliografía}

\section{Fuentes Primarias}

Constitución de 1980 (1981). Santiago: Editorial Jurídica de Chile. Segunda Edición.

Declaración acerca de los detenidos desaparecidos (1982). Comité Permanente de la Conferencia Episcopal de Chile. 9 de noviembre, 1978. En: Documentos del Episcopado. Chile 1974-

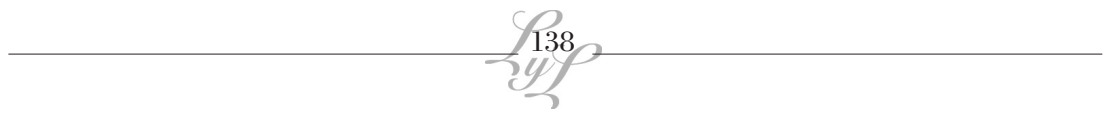


1980 (1982). Secretariado General de la Conferencia Episcopal de Chile. Santiago: Ediciones Mundo Ltda.

Declaración de Principios (1974). Santiago: Editora Nacional Gabriela Mistral.

"Anoche en Chacarillas S.E. indicó Grandes Líneas Institucionales" (1977). Santiago: Diario El Mercurio: 33.

Mensaje Presidencial. Santiago: 1975.

Objetivo Nacional del Gobierno de Chile. Santiago: 1975.

Realidad y Destino de Chile (1973). Santiago: Editora Nacional Gabriela Mistral.

Visión Futura de Chile (1979). Santiago. División Nacional de Comunicación Social.

\section{Fuentes Secundarias}

Ahumada, E. et al. (1989). Chile: La Memoria Prohibida. 3 volúmenes. Santiago: Pehuén Editores, tomo III.

Arancibia, P. y F. Balart (2006). Conversando con el General Julio Canessa Robert. Santiago: Editorial Biblioteca Americana.

Barros, R. (2005). La Junta Militar. Pinochet y la Constitución de 1980. Editorial Sudamericana, Santiago.

Braudel, F. (2002). Las Ambiciones de la Historia. Barcelona: Editorial Crítica.

Burke, P. (2006). ¿Qué es la Historia Cultural? Barcelona: Paidós.

Cavallo, A.; M. Salazar y O. Sepúlveda (1989). La Historia Oculta del Régimen Militar. Chile 1973 - 1988. Santiago: Editorial Antártica S.A.

Cristi, R. (2000). El Pensamiento Político de Jaime Guzmán. Autoridad y Libertad. Santiago: LOM Ediciones.

House, E. R. y K. R. Howee (2001). Valores en Evaluación e Investigación Social. Madrid: Ediciones Morata.

Halliday, M.A.K. (1994). El Lenguaje como semiótica social. La interpretación del lenguaje y del significado. Bogotá: FCE.

Jaeger, S. (2003). "Discurso y conocimiento: aspectos teóricos y metodológicos de la crítica del discurso y del análisis 
Las macroformas textuales de los Derechos Humanos. Chile, 1973-1980 / Freddy Timmermann

de dispositivos". En Wodak-Meyer (2003). Métodos de análisis crítico del discurso. Barcelona: Gedisa.

Harrington, E. y M. González (1987). Bomba en una Calle de Palermo. Santiago, Editorial Emisión.

Huneeus, C. (2000). El Régimen de Pinochet. Santiago: Editorial Sudamericana.

Kerbrat-Orecchioni, C. (1997). La enunciación de la subjetividad en el lenguaje. Buenos Aires: Edicial.

Le Goff, J. y R. Chartier y J. Revel (1988). La Nueva Historia. Bilbao: Editorial Mensajero.

Martorell, F. y M. Guerra (2003). "Lo que la DINA escribió sobre Jaime Guzmán”. El Periodista, n³ 38, 22 de junio.

Pellegrino, U. (1983). Diccionario Teológico Interdisciplinar. Salamanca: Ediciones Sígueme, tomo IV.

Pinochet de la Barra, O. (1987). El Cardenal Silva Henríquez. Luchador por la Justicia. Santiago: Editorial Salesiana.

Procacci, G. (2001). Historia General del Siglo XX. Barcelona: Editorial Crítica.

Salazar, M. (1994). Guzmán. Quién. Cómo. Porqué. Santiago: Ediciones BAT.

Ricoeur, P. (2008). El conflicto de las interpretaciones. Ensayos de hermenéutica. Buenos Aires: F.C.E.

Santibáñez, A. (1978). Sin Novedad en el Beagle. Santiago: Revista Hoy, ${ }^{\circ}$ 82, 20-26 diciembre.

Timmermann, F. (2005). El Factor Pinochet. Dispositivos de poder, Legitimación, Elites. Chile, 1973-1980. Santiago: Ediciones Universidad Católica Silva Henríquez.

(2008). Violencia de Texto, Violencia de Contexto. Chile, 1973. Santiago: Ediciones Universidad Católica Silva Henríquez-Centro de Investigaciones Barros Arana.

(2009). La Declaración de Principios de la Junta Militar. Chile, 1973-1980. Tesis de Grado Doctor en Historia. Universidad de Chile (sin publicar).

Valenzuela, A. (1993). "Los Militares en el Poder: la Consolidación del Poder Unipersonal". En Drake, P. e I. Jaksic (1993). El

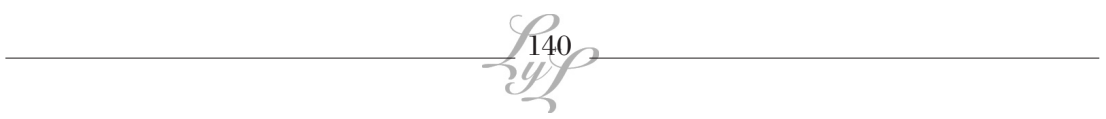


Difícil Camino Hacia la Democracia en Chile 1982-1990. Santiago:FLACSO.

Van Dijk, T. (1997). Estructuras y Funciones del Discurso. Ciudad de México: Siglo Veintiuno.

Vergara, P. (1985). Auge y Caída del Neoliberalismo en Chile. Santiago: FLACSO.

Wodak, R. (2003). "De qué trata el análisis crítico del discurso (ACD). Resumen de su historia, sus conceptos fundamentales y sus desarrollos". En Wodak-Meyer (2003). Métodos de análisis crítico del discurso. Barcelona: Gedisa. 